\title{
Article \\ In Service of News Subscribers: Exploring Belgian Journalists' Perceptions of Stakeholder Relations in the Digital News Ecosystem
}

\author{
Dorien Luyckx*(i) and Steve Paulussen
}

check for

updates

Citation: Luyckx, Dorien, and Steve Paulussen. 2022. In Service of News Subscribers: Exploring Belgian Journalists' Perceptions of Stakeholder Relations in the Digital News Ecosystem. Journalism and Media 3: 81-98. https://doi.org/ 10.3390/journalmedia3010007

Academic Editor:

Andreu Casero-Ripollés

Received: 7 December 2021

Accepted: 10 January 2022

Published: 15 January 2022

Publisher's Note: MDPI stays neutral with regard to jurisdictional claims in published maps and institutional affiliations.

Copyright: (C) 2022 by the authors. Licensee MDPI, Basel, Switzerland. This article is an open access article distributed under the terms and conditions of the Creative Commons Attribution (CC BY) license (https:// creativecommons.org/licenses/by/ $4.0 /)$.
Department of Communication Studies, University of Antwerp, 2000 Antwerp, Belgium; steve.paulussen@uantwerpen.be

* Correspondence: dorien.luyckx@uantwerpen.be

\begin{abstract}
This qualitative paper contends that as news media are faced with growing commercial pressures and changing news consumption habits, they need to rethink their relationship with two of their main stakeholders: readers and advertisers. Multi-stakeholder marketing provides a useful conceptual framework for such an exercise, since it invites media practitioners to reconcile the conflicting interests of different stakeholders. This study aims to understand journalists' levels of multi-stakeholder thinking regarding advertisers and readers. To explore how contemporary journalists see their role with regard to distinct stakeholders in the news ecosystem, we interviewed 14 Belgian journalists working for legacy and digital native news media. The goal of this exploratory study is to examine (1) how journalists perceive and rethink their dependence on readers and advertisers in the digital news ecosystem and (2) how their perception of the digital news ecosystem influences their attitudes towards these stakeholders. Findings indicate that journalists tend to see the value of readers in monetary terms and believe increasing reader revenue will help journalism survive. Other types of reader value (feedback, expertise, and content) are peripheral. This focus on subscribers also seems to coincide with a devaluation of other stakeholders like advertisers and non-paying readers.
\end{abstract}

Keywords: stakeholder marketing; news media; news business studies; subscribers; advertising

\section{Introduction}

Like any company, a news organization does not exist on its own but is always part of a complex ecosystem of interdependent stakeholders exchanging value between one another (Hillebrand et al. 2015). However, unlike other companies, news media are typically characterized by their pursuit of both democratic and financial goals. To avoid that the interests of advertisers (commercial) would collide with those of readers (democratic), commercial news media have traditionally separated their advertising departments from the newsroom (Lauerer 2019). This model has been predominant and stable in the news industry in the 20th century and has kept the news business a solid industry while at the same time providing independent journalism at an affordable price (Picard 2014). Meanwhile, these democratic goals have been cemented in journalists' role perceptions to remain independent of commercial influences (Deuze 2005).

However, further commercialization and the rise of platforms at the beginning of the 21st century have created a much more unstable stakeholder system that has urged news companies to reconsider their relationships with readers and advertisers. Advertisers have been pulling their ads from news sites in favor of new digital players (McNair 2018), while readers are showing a decreased willingness to pay for news (Costera Meijer 2020; Swart et al. 2018; Chyi and Ng 2020; Rosen 2006). Faced with the double commercial challenge of attracting readers and advertising revenue, news media saw the need to 
develop a new value exchange between their stakeholders to support journalism in a sustainable way.

This comes with a redrawing of the internal separation between the commercial and editorial side of news media, as editors and managers consider it a hurdle for innovation (Cornia et al. 2018). Newsrooms are the departments at news media that pursue democratic goals, but the increasing commercial pressure on newsrooms has been troubling journalism researchers, as this can interfere with the democratic role of news media by blurring the line between commercial and editorial content in the shape of native advertising (Amazeen and Wojdynski 2019), by reducing the number of journalists (Trappel and Tomaz 2021), and by sacrificing quality over quantity, which has led to clickbait and churnalism (Jackson and Moloney 2016). In contrast, studies into entrepreneurial journalism have argued that journalists need to be involved more in the business side of news media in order to create a sustainable future, but the lack of a strategic framework to do so without sacrificing their democratic role makes it difficult for journalists to navigate this duality (Rafter 2016; Vos and Singer 2016).

Marketing scholars have argued that stakeholder marketing has been proven to be useful in other industries (e.g., green energy and education) for incorporating their societal roles alongside their financial goals (Driessen and Hillebrand 2013; Laczniak and Murphy 2012), but stakeholder marketing has not yet been studied in a news media context. Moreover, some researchers argue that a need exists for a strategic framework that encompasses both the editorial and commercial side of news media instead of separating the two (Nielsen 2016; Picard and Lowe 2016; Küng 2016). Therefore, this study explores how a stakeholder marketing lens (Hillebrand et al. 2015) can enhance our understanding of a newsroom's relationship with its stakeholders.

With this qualitative study, we want to delve deeper into how the journalists of today perceive the news ecosystem with its value exchanges, stakeholders, and tensions. By zooming in on those stakeholders that are important for the financial and democratic wellbeing of the news company (advertisers and readers), we explore how journalists deal with this duality - pursuing revenue while performing independent journalism with the following research question and sub-questions.

RQ: How do contemporary journalists see their role with regard to distinct stakeholders in the news ecosystem?

(a) Who do journalists see as key stakeholders in the digital news ecosystem?

(b) How do journalists perceive the importance of readers and advertisers for the business of news?

(c) How willing and capable are journalists to apply multi-stakeholder thinking regarding readers and advertisers?

\section{Theoretical Framework: A Multi-Stakeholder Perspective}

\subsection{The News Ecosystem: Stakeholders, Value Exchange, and Tensions}

Value creation in the business of news targets three key stakeholders, namely publishers, advertisers, and readers (Gustafsson 2006). While news publishers obtain revenue from selling journalism and advertising space, advertisers get access to an audience and readers can consume news freely or at a low price. These three stakeholders have an interdependent relationship with one another, in which compromises are made to offer enough value for each stakeholder. However, since both advertisers and readers have been shifting their attention and budgets to online platforms, news publishers' business models are under severe pressures (Chyi and Tenenboim 2017; McNair 2018).

To restore lost revenue, news media have taken different avenues to create a new value exchange. Some news organisations like the New York Times were able to chase scale while more or less maintaining their traditional revenue system of subscriptions and advertising; however, scale has also led to several mergers and buy-outs in the past decade, creating media markets largely dominated by a handful of media conglomerates (Trappel and Tomaz 2021). Other news organisations introduced advertising products like 
native advertising that created new value propositions, but also new tensions between stakeholders that have not been resolved to date (Taylor 2017; Han et al. 2018; Carlson 2015; Aribarg and Schwartz 2019). Moreover, tensions with advertisers have led to a renewed focus on reader revenue, mainly leading to paywalls that limit access to quality news in favour of market-driven goals (Benson 2018). As an alternative to paywalls, some news media have been redefining their relationship with readers via crowdfunding, membership models, or shareholder systems built on engaged journalism (Wenzel and Nelson 2020; Schmidt et al. 2020).

Many of these new strategies result in new tensions with readers and advertisers. For instance, implementing paywalls requires publishers to determine what value they actually offer their readers in exchange for money. Although the majority of people recognize the importance of news media in society (Walker et al. 2018), only a fraction of them is still willing to pay for online news (Chyi 2005; Fletcher and Nielsen 2017; Skibinski and Rande 2019; Chyi and Ng 2020). Studies suggest that paywalls often lead to frustration among readers (Cziehso 2017) and activate the so-called penny gap-even having to pay 1 cent makes people wonder if it is worth it (Chyi 2012).

Some advertising formats have become a source of frustration for readers (Pujol et al. 2015; Carlson 2015; Goldstein et al. 2014). Currently, readers signal their dissatisfaction with online ads by using ad blockers against targeted ads, and intrusiveness and tracking by third parties online by fleeing to ad-free alternatives and by showing an increased attention regarding privacy and data protection (Wielki and Grabara 2018; Goldfarb and Tucker 2012). Moreover, we have seen the emergence of new advertising types, like native advertising, which is online advertising that matches the form and function of editorial content. These advertising types create new tensions between publishers and readers (Wojdynski 2016).

As illustrated above, the survival of news organisations depends on a complex and delicate value exchange system. As we will argue below, in order to face the challenges of the rapidly changing news ecosystem, news publishers might benefit from a more stakeholder-inclusive mind-set.

\subsection{Stakeholder Thinking at News Media}

Within marketing research, stakeholder marketing theory posits that companies should include all important stakeholders and use the stakeholder ecosystem to their advantage (Frow et al. 2014; Hillebrand et al. 2015; Hult et al. 2011). Crucial to this approach is that the whole company has to focus on a network of active stakeholders (systems thinking) and accept and learn from tensions among stakeholders (paradoxical thinking), in order to co-create value (rather than interact in dyadic relationships) and strengthen the ecosystem by sharing control with these stakeholders (democratic thinking).

Not all stakeholders carry equal weight in the ecosystem, so it is useful to make a distinction between primary and secondary stakeholders. Primary stakeholders are "those groups the firm depends on for its survival and continued success" (Hult et al. 2011, p. 49). Hult et al. (2011) identified six primary stakeholder groups, namely customers, suppliers, employees, shareholders, regulators, and community members, ranked by importance following the power/interest grid defined by Mitchell et al. 1997). Secondary stakeholders are those that "influence or affect, or are influenced or affected by, the corporation, but they are not essential for its survival" like competitors, trade associations, mass media, and social media (Clarkson 1995, p. 107).

Stern (2008) elaborated how stakeholder thinking could be important for news media, but no further research has been dedicated to transferring the insights of stakeholder thinking from the marketing field to the context of news media. Stakeholder thinking could be especially useful for companies that take a social responsibility besides their commercial objectives, as this requires a dialogue with the surrounding stakeholders (Driessen and Hillebrand 2013; Huempfner and Kopf 2017).

As stakeholder thinking is particularly focused on dealing with tensions between stakeholders, this marketing field could be an interesting addition to studying the business 
of journalism. Internally, news media are struggling with the increasing tensions between their editorial and commercial sides. The traditional setup at news media to protect the newsroom from these tensions was a clear separation between the commercial and editorial sides of news media, represented by the metaphorical concepts of a "wall" or the "separation of Church and State" (Coddington 2015; Lauerer 2019). However, a long tradition of scholarly work has pointed out the fallibility of such a divide (Artemas et al. 2018; Coddington et al. 2018; Lewis et al. 2008).

Several studies have showed how this framework is slowly being replaced by a culture of "collaboration, adaptation and business thinking", where working with other parts of the news medium is considered necessary by editors and business managers to ensure commercial sustainability (Cornia et al. 2018; Westlund et al. 2021). Many recent developments like native advertising, cross-functional product development, and entrepreneurial journalism have instigated the further blurring of these lines, creating internal tensions between commercial and editorial departments (Coddington 2015; De Smet and Vanormelingen 2011; Hanusch et al. 2020; Artemas et al. 2018). Merging these two sides is still a fairly new development, and yet some consider it vital for survival in a digital age (Laursen 2018; Newman 2019; Picard 2015; Vos and Singer 2016). However, it is not always accepted (Boyles 2016; Holton 2016), nor without challenges (Carlson 2015; Carroll 2019; Taylor 2017). Moreover, the financial insecurity of news media has not only increased the existing tensions between commercial and editorial goals, but has also led to journalists internalizing these objectives (Artemas et al. 2018; Vos and Singer 2016). The study by Duffy and Cheng (2020) showed how, regarding the commercial-editorial relationship, editors are being "torn between the old (ethically driven) norm of how things should be, and the emerging (economically driven) norm of how things are" (p. 1).

A lot of scholarly work has focused on studying these changes and their effects on newsrooms, but little research dedicates itself to expanding our understanding of these tensions by exploring possibly effective frameworks from other research fields that can encompass both the business and editorial sides of journalism. It is detrimental to research the ethical challenges of this closer collaboration between commercial and editorial departments. Moreover, it seems to become everyday practice at many news media of the global north, so studying strategies that can guide this collaboration without compromising the democratic purpose of news media by the commercial goals of the news business are necessary as well. As stakeholder thinking is particularly focused on dealing with these types of tensions, this marketing method could be an interesting addition to the studying of the business of journalism.

For the news industry itself, adopting a stakeholder perspective can help news media develop a sustainable and balanced compromise between all its stakeholders, which may not be perfect but as a whole performs best for all involved. It also implies collaboration throughout a company with all important stakeholders, such as readers and advertisers. Digitalisation and commercialisation have led to increased pressures on journalists to change their role perceptions to accommodate this new environment. Scholars have argued that journalists should play an increasing role in the commercial decision making within the news company, as news companies have to take into account both their financial and journalistic well-being (Rafter 2016). However, are journalists prepared to take up this role?

\subsection{Journalists' Role Perceptions}

The digitalisation and commercialisation of news has impacted newsrooms immensely and has led to organisational transformations and changing practices ever since the turn of the millennium, putting high pressure on journalists to reconstruct their professional role (Cottle and Ashton 1999; Witschge and Nygren 2009). This led to important changes to journalists' role perceptions in relation to other primary stakeholders within the news ecosystem, such as the publisher (e.g., job cuts, newsroom metrics, and business model), readers (e.g., user-generated content, social media, and comment sections), and advertisers (e.g., native advertising, churnalism, and commercial pressure). As outlined by Stern (2008), 
and a strong scholarly tradition, news companies have a broad range of stakeholders, but not all of them are equally influential. Strömbäck and Karlsson (2011) surveyed journalists on the changing influence of other actors, such as media owners, advertisers, and the audience. They noted how journalists at the time believed that media owners especially had increased their influence, followed by the audience and advertisers, but that journalists still remained in control.

In line with this, Meyen and Riesmeyer (2012) developed a typology of role perceptions that showed how some journalistic roles allowed for more influence of these stakeholders. For example, "service providers" want to connect with the audience, "traders" look at the audience as customers, and "promoters" try to include advertisers' needs. Despite being employed in an editorial department, these promoters no longer saw themselves as journalists. Since then, the increasing digitalisation of the newsroom, the further decline of advertising revenue, and the low willingness to pay among readers have reshaped journalistic roles further. Grubenmann and Meckel (2017) concluded that some journalists take this more "service-oriented" approach in an attempt to improve journalism online. In this study, digitalization was considered a threat by one group, whereas the other group took on a more "solutions-oriented" role. This might suggest that online journalists think more strategically than their peers in print.

In the past decade, technological developments and financial interests have continued motivating journalists to rediscover their audience while reimagining their relationship (Ferrer-Conill and Tandoc 2018; Lamot and Paulussen 2020; Loosen and Schmidt 2012; Hermida et al. 2011). Still, tensions between civic and citizen demands seem to temper the enthusiasm among journalists for giving the audience too much influence (van der Wurff and Schoenbach 2014; Johnson and Dade 2019; Duffy et al. 2018). Moreover, new services focused on readers' needs like news aggregators (Jeon and Nasr 2016) or comment sections (Ksiazek et al. 2015) have had a negative impact on newsrooms and individual journalists as well, tempering the enthusiasm to pull readers closer (Lewis et al. 2020). This interplay between readers and online journalists seems to also determine journalists' behaviors. Coddington (2018) showed how journalists' perceptions of their audience's technology demands were related to a higher use of those technologies by these journalists. These recent studies seem to continue resonating a long-established division among journalists between those exploring the all-audience-related opportunities of the internet and those who remain hesitant to change their journalistic role (O'Sullivan and Heinonen 2008).

The same goes for commercial developments for news media online. There seems to be a strong innovation-oriented discourse among journalists that might influence their role perceptions, but when studying the interpretative repertoires of journalism students, they still seem to hold on to traditional views of journalistic roles (Singer and Broersma 2020). In the meantime, advertisers, ad departments, and media executives have increased the pressure for news media to create an advertiser-friendly environment (Artemas et al. 2018; Bærug and Harro-Loit 2012; De Smet and Vanormelingen 2011; Hanusch et al. 2020; An and Bergen 2007). Advertisers are moving from the side-line (banner ads) to a more embedded role with native advertising and online advertising that matches the form and function of editorial content (Wojdynski 2016). In contrast to display ads, native advertising demands a much closer interaction with the advertiser, resulting in the development of content studios within news media. Corporate or commercial pressure has increased across western newsrooms and, as Hanitzsch (2011) argued, this makes journalists feel less autonomous in their profession.

It might explain why journalists remain quite sceptical in regard to commercial and strategic activities, as these threaten their autonomy, one of the five journalistic core values (Deuze 2005). If they allow commercial goals and audience members to steer their decision making, do journalists still have power over their own newsroom? This tension between market orientation and professional autonomy resonates across different studies.

Sharing power over decision making with important stakeholders is one of the three main skills of stakeholder thinking. If journalists see commercial activities and audience- 
centric product development as a threat to their autonomy, implementing stakeholder thinking throughout news media becomes challenging. As Costera Costera Meijer (2020) argues, what the audience sees as valuable journalism might not correspond with what journalists perceive as valuable journalism, so some co-creation of value might be necessary to assure a sustainable future for journalism. However, systems thinking, paradoxical thinking, and democratic thinking build on each other, so even though journalists might not yet include other stakeholders in their decision making (democratic thinking), being aware of the stakeholder system, its value exchanges and stakeholders (systems thinking), and seeing the tensions between stakeholders as possible opportunities to innovate (paradoxical thinking) are important parts as well (Hillebrand et al. 2015).

Stakeholder thinking has been shown useful to help organizations deal with tensions between ethics and business. This strategy can create a new balance in the value exchange between the key stakeholders surrounding the news medium without the compromising of democratic goals by commercial ones while the different departments are moving to work closer together. Newsrooms and their journalists are a major internal stakeholder of news media. Therefore, it is important to start with this stakeholder to explore possible opportunities for stakeholder marketing to tackle the challenges of the business of journalism.

\section{Methodology}

To explore journalists' perceptions of the influence of different stakeholders in the news ecology, we conducted 14 semi-structured face-to-face interviews with journalists working at news media organisations in Flanders, the northern, Dutch-speaking part of Belgium. Three journalists worked at digital-first news outlets, while the other 11 worked at legacy news organisations. The sample contained interviewees from four different Flemish legacy news media and from two digital-first news outlets that have the dual revenue model (audience and advertising revenue). The Flemish public broadcaster and news media that only focus on audience revenue were excluded, because we wanted to expand our understanding of how journalists deal with the tensions between advertisers' and readers' needs. We consider the selected interviewees as experts to report on the business of news from their experience and perspective as a part of the newsroom. Four interviewees had a leadership position as either editor-in-chief or managing editor; the other interviewees were employed as (online) journalists. We focused only on people active at the newsroom, because we wanted to avoid combining commercial and editorial profiles in the sample to focus our attention on the point of view of the editorial part of news media. The interviews took place between November and December 2018. Each interview took between one hour and an hour and a half. Semi-structured interviews were chosen as an adequate research method to reveal journalists' complex (explicit and implicit) perceptions of the ecosystem, its value exchange, and stakeholders (Flick 2018).

The first part of the interview was recorded-audio only. Using a stakeholder marketing lens, we based the interview protocol (see Appendix A) on three main topics: How does the interviewee see the news ecosystem (stakeholders, value exchange, and boundaries)? What tensions exist between stakeholders? How do journalists handle these tensions? The interview guide was constructed in such a way that at the beginning we did not guide the interviewee to point out stakeholders to avoid limiting the interview on the researcher's preconceived importance of certain stakeholders that might not have been correct. For each identified primary stakeholder, we asked the same set of questions to create a fuller picture of their perception of this stakeholder.

For the second part, the interviewee received a copy of the power/interest grid by Mitchell et al. 1997), translated into Dutch, and cards of 15 stakeholders (readers, advertisers, publisher, social media, platforms, policy makers, politicians, sources, subscribers, suppliers, news media, interest groups, journalists, customers, and shareholders). The interviewee was asked to map the different stakeholders onto the grid according to their view on the matter. If other stakeholders were mentioned during the first phase, these cards were created and added to the mix as well. The grid allowed the interviewee to 
compare and determine a position for each stakeholder, because it is a more fixed way of representing the stakeholder network. While they explained the position of the different stakeholders, we asked the interviewees to judge the positions based on their point of view: Has it always been like this? Will it be the same in the future? Is this the ideal situation? What should change? To this end, we also gave the interviewee a card with their group "journalists" to place among the stakeholders and explain that position. The interaction with the grid was filmed with the camera pointed at the grid to capture the nuance of hand gestures and the moving of cards to the maximum extent.

We transcribed the interviews and coded them, first openly, then axially, and finally selectively, following grounded theory (Corbin and Strauss 1990) to develop a codebook in NVivo, from which to derive new insights and concepts as presented below. The codebook was structured per mentioned stakeholder with subcategories for the (by journalists') perceived needs, tensions, and relationships. We used the stakeholder marketing theory as an analytical lens to evaluate to what extent journalists engage in systems thinking, paradoxical thinking, and democratic thinking based on how they talk about certain stakeholders.

\section{Results}

\subsection{Journalists' View of Their Main Stakeholders}

In the first part of the interviews, the journalists were asked what they perceived to be the main stakeholders in the news ecology. All of them mentioned readers as a primary stakeholder. Some interviewees stated that "the reader is the one we work for" (j04) and "that's the most essential part: the bond with our readers and everything that comes from that" (j03). Besides readers, the journalists recognized sources: "They [sources] have more influence, because we don't have news without them" (j02) and advertisers: "Advertisers ... they have influence, because they bring in the money" (j13) as important stakeholders.

For instance, sources are seen as valuable, because they help build news stories to attract an audience. They are considered an important stakeholder for journalists to fulfil their role in regard to the audience: creating trustworthy and interesting content. As sources are so detrimental to the act of news bringing, journalists assign them quite some influence: "Of course, they have a lot of influence. Those are the people from whom we get our info" (j11). This creates a reciprocal relationship with possible tensions as well. For instance, journalists talked about a symbiotic relationship of give and take between journalists and politicians as sources. There seems to be a value exchange that has been carefully balanced with internal and external checks in place to ensure the editorial independence on the one hand, and to maintain a fruitful source of information on the other hand.

"They [politicians] are our source, but at the same time the people we write about. We need to question power and the parties performing that power [...] That creates an antagonistic relationship." (j09)

A fourth set of actors that are considered as main stakeholders are social media. During the interviews, journalists referred to the social media platforms as major stakeholders in the digital media ecology. Social media were seen as an important channel to increase brand awareness and pull traffic from these platforms towards their own news sites. Their power is measured in the traffic they sent towards news sites. The interviewed journalists identified the influx of news content as the value they offer to social media platforms in exchange for this traffic, but many explained that most social media platforms work fairly independent of them, making newsrooms vulnerable and dependent. These interviewees did not consider their news company large enough to be considered as a proper stakeholder by social media platforms, leaving them in a more vulnerable position, especially when their news medium is dependent on traffic from social media platforms.

"They impact the wellbeing of the company. Three quarters of our traffic comes from social media. [...] It makes you incredibly vulnerable by being so dependent on them. It puts you in a vulnerable position." (j14) 
Moreover, this goal of increasing traffic away from social media platforms is against the interests of certain social media platforms, which has led to algorithmic changes that downplayed news content. Moreover, some interviewed journalists feared that a high dependency on these platforms could lead to identity loss. As a result, interviewees explained how their news medium is trying to reduce its dependence on these platforms by focusing on direct distribution (via search among others). Social media platforms that support this goal of attracting traffic are evaluated more positively and newsrooms actively optimize their news stories for these platforms.

"Facebook has shot itself in the foot, because with the algorithm changes news media have said 'ok, we need to be less dependent on Facebook' and evidently their influence decreases as well." (j08)

"You only want to use Facebook as a billboard for your content, but people have to come to your platform." (j07)

"If our SEO isn't good, people won't find us online. Then we're screwed. [ . . . ] a large part of our traffic comes from search [ ... ] so we need to keep in mind the requirements of Google to index our website." (j02)

While interviewees seemed to agree that the economic survival of digital news media is dependent on readers, sources, advertisers, and social media platforms, some interviewees also mentioned the government and the media company's shareholders as stakeholders. These stakeholders had a more passive role. Shareholders seem to keep their distance as long as the main business goals are met, but turn up the heat when this isn't the case: "If the shareholder isn't happy or notices that profits are decreasing, this will have repercussions for the newsroom. Not that they'll come whip us, but our budgets will be cut." (j06). Interviewees noted that the government influenced changes in the news industry via subsidies to mostly larger news media, leading to discontent among smaller players: "It's mainly the big companies [...] we're just shrimps. [...] Every once in a while, we get some crumbs." (j14)

Journalists, in line with previous research, still have a traditional view on their role as journalists in regard to readers and advertisers. According to them, journalists are there to serve readers with trustworthy and interesting news stories. Advertisers were seen as a primary stakeholder as well, but were not perceived as a function of creating a good service for readers. An indifference, but also pragmatism, prevailed when the interviewed journalists talked about advertisers. The interviewees saw themselves completely detached from this stakeholder and wanted this detachment to be maintained at all costs, while at the same time they recognized their monetary value for them. To allow a relationship, they referred to the publisher's side of the news medium that should deal with advertisers and their needs. Despite research showing that the Chinese wall is more of a "curtain" (Coddington 2015), the journalists we interviewed maintained that clear separation in their role perception. In the following paragraphs, we will delve deeper into how they perceive their relationship with readers and advertisers.

\subsection{In Service of the Subscriber}

When asked about their relationship with readers, interviewees mentioned several value propositions they offer to convince readers to engage with their news content. First and foremost, getting access to quality news reporting. According to the journalists we spoke to, readers want correct and quality information to remain up to date on a wide array of relevant topics. Readers expect that this news service is accessible regarding price, lay-out, writing style, channel (online, offline), and type of medium (video, text, and audio). Journalists said that by reading or subscribing to content, people accept "their lens on the world's events" (j09). This way, readers identify with the news medium and engage with it, while becoming a part of their socially involved community. The provided news service should not only keep people up-to-date, but should also be personally relevant, giving access to in-depth reporting, expertise, and crucial information for readers' daily 
work and lives. Besides information, journalists believed readers also wanted to be entertained, amused, and surprised. In this line of thought, journalists saw themselves as service providers.

Digitalization enables more interaction with readers and the creation of other value propositions that readers can offer news media besides money, such as feedback, support, or engagement with their content, but despite recognizing their role as service providers, this did not lead to a stronger connection with the audience, as was shown in previous research (Meyen and Riesmeyer 2012). In general, they said that they kept readers at a distance. Some projects to engage readers in the news production cycle were seen as positive examples, but no long-lasting reciprocal relationships were being developed at their newsrooms. The mentioned projects were of a collaborative nature (e.g., a citizen science effort to collect data on air quality) or requests by the newsroom to send in stories or content regarding a certain topic. According to the interviewees, these projects mainly offered prestige to the newsroom and recognition by their peers, generated new content or led to other stories, helped to connect with the audience, and attracted new subscribers. Despite this added value, these projects were called exceptions and did not lead to their newsroom implementing learnings to increase audience engagement and were thus deemed by them and their newsrooms as nice-to-have, but not essential. So, the interviewees recognized that the ways to connect with readers stayed limited to mainly one-way streets. On top of that, interviewees dismissed the value of commenters because they were "a small minority of our readership" (j11) that "did not have a subscription" (j01). As j08 put it: "Many of my colleagues believe they represent the reader, but barely any of them truly interacts with them" and other interviewees pointed out that engaging with readers online "is not part of their job" (j04). Interviewees also explained that managing the comment section was done by a community editor or moderator. It was this person's task to engage with the audience.

Journalists also seemed to emphasize the monetary value of readers: subscribers and clicks (depending on their revenue model) bring in money to support their reporting. Some journalists at ad revenue-focused media mentioned how a higher number of comments meant more traffic and thus more ad revenue, so they argued that news media turned a blind eye to tensions arising in the comment section in favor of higher ad revenue. Other interviewees mentioned how failing advertising revenue led to a stronger focus on subscribers throughout the newsroom, leading to a higher influence of subscribers. This monetary value of readers has become crucial for newsrooms because of the low WTP for news and the loss of digital ad revenue for news media, so the adoption of subscribers as their target audience might be considered a necessity to survive. For instance, interviewees spoke negatively of the past strategic decision of news media to offer free access to news. According to them, this has been a key factor for people's low willingness to pay for news today.

\section{"Digital doesn't work as it should, because people have gotten news for free for years and} it's hard to stimulate them now to pay." (j06)

"I saw someone share on Facebook a news story and somebody asked for screenshots because they couldn't open it. [...] that's the opposite of what the newspaper wants: people sharing without paying." (j12)

This strong focus on the monetary value of readers was also noticeable in how the interviewees spoke more positively of subscribers than non-paying readers: "They [readers] are not the target audience you keep in mind. Your target audience are the interested people who pay." (j12). Despite interviewees mentioning how they maintained a wall to separate themselves from commercial departments, subscribers were being considered by several interviewees as their target audience, rather than the larger group of readers. The concept of subscribers comes from a commercial setting, which might seem in contrast with the active denouncement of commercial activities by the interviewees. Implementing commercial concepts creates a tension between newsrooms' stances on strictly separating business and journalism. To resolve this tension, the interviewees seem to adjust their conceptualization 
of subscribers to fit their journalistic goals. Non-paying readers were considered passers-by: "It's a challenge to tie young people to your brand. [...] Young readers come to you via social media to read a piece. How do you tie them to you and how do you get them to pay?" (j10) or reluctant payers: "People don't feel like paying for news" (j12), "some people pretend as if journalists need to work for free, [...] but you have to get paid" (j10). This group was seen as less essential to the newsroom, whereas subscribers were seen as "loyal" (j05, j10), "by definition fit with what we do" (j01), and aligned with the newsroom: "We offer something and the readers follow us in that" (j11) and are "part of the club" (j09). Taking a subscription was considered "the ultimate vote of confidence" (j09).

This focus on subscribers also seems to lead to more power for paying readers. Many interviewed journalists mentioned how subscribers exert more influence, because they can signal their dissatisfaction by cancelling their subscription, which gives them more power over editorial decision-making than readers. Moreover, the more a news medium becomes dependent on subscribers as their main revenue source, the stronger the influence this stakeholder will have on the output of the news medium. However, readers were still mostly considered as one mass. Power comes with number, both in how they are measured and served. Individually, readers are deemed powerless and they only influenced the newsroom of our interviewees if subscriptions or visits dropped significantly (depending on the revenue model).

Journalists try to align this renewed focus on subscribers with their traditional role perception of providing trustworthy, accessible, and interesting news stories as they believe their paying audience seeks the same things. Moreover, claiming beats by producing journalism focused on a particular issue, sector, organization, or institution over time seems to have become a part of the marketing strategy to obtain subscribers, as j10 noted that by promoting their expertise in certain beats over a couple of months, their subscriber base increased. When asked if they believed these were new news subscribers or merely converted subscribers from other media, this interviewee replied that "it is likely we attracted subscribers from other news media".

\subsection{What about the Advertisers?}

All interviewees were active at news media that had a dual revenue model of both reader and advertising revenue, but interviewees pointed out how social media platforms have drained the digital advertising revenue from news media and how their news medium now strives to increase their subscription revenue rather than focus on advertising revenue.

"We [the newsroom] defended the readers, from the advertising department [... ] that clashed. Now, the more subscribers contribute to our revenue, the easier to say subscribers belong here [high influence, high power spot] on power/interest grid." (j08)

The value of news media for advertisers is defined by them as reach: "[Advertisers] can surf along on the newsroom's reach" (j11), as a reputation spill-over effect: "The advertiser wants to spin it and connect themselves to the news medium's quality image" (j02), or as in-depth knowledge of a niche audience and how to reach them. In the other direction, interviewees approached the value of advertisers for themselves pragmatically and single-minded. If it is a large revenue source to sustain their journalism, advertisers are considered a stakeholder, and if the advertising revenue decreases they would rather terminate the relationship than look for ways to reinvigorate it. This position seems driven by the perception that advertisers are a threat to independent coverage and thus any direct relationship between journalists and advertisers has to be rejected. Interviewees also expressed that advertisers desire to have a direct influence over the editorial output and thus have to be kept far away from the newsroom. The interviewees rejected close contact with the advertiser, even though they do acknowledge the monetary value of advertisers. They still referred to the established relationship between a news medium and advertisers, as the "Chinese wall" between the newsroom and commercial departments. They explained how commercial departments take care of any issue related to advertisers and the newsroom can keep its distance from advertisers. This wall, according to them, 
also exists on the news site. According to some, news content and advertorial content are clearly separated via layout and location on the news site and yet, depending on what spots are sold, the layout of a news site changes.

Journalists at legacy media were also very critical of native advertising, as it tends to deceive the reader and take advantage of the medium's reputation of independent reporting. They are very skeptical of this ad format and see it only as an advertising product and thus do not want to be involved in its development, nor do they take responsibility over native advertising. They also vigorously defended clear labelling to separate their content from advertising content.

"They're pushing it [native advertising] quite far, that people can't recognize it anymore and then people feel cheated. I understand from the point of view of the media company that this helps convince advertisers [...] but in the long run, you're just hurting yourself [the media company]." (j12)

Some journalists felt strengthened in their aversion toward advertisers thanks to the growing subscription revenue. Some interviewees voiced sympathy for readers' ad blocking behaviors, even though their news medium tries to discourage ad blocker usage: "Go for it, block it. [...] no worries. [readers] are more important to me than advertisers." (j01). They reflected back on a worse time before, when the newsroom still had to fight and stand their ground against the influence of advertisers: "Things that were clearly separated in print, a few years ago we had to fight that fight again digitally." (j08). However, many still voiced active vigilance to keep the advertiser in check now, as commercial pressure did not decline.

"From what I hear and see, there seems to be more [commercial] pressure at news media." (j11)

"We made some agreements in the news company. If our newsroom detects that lines are being crossed, we'll intervene." (j07)

"We feel that revenue stream shrinking and that creates tensions and unrest for the future." (j05)

"Advertisers can increase the pressure, but I'll always push back." (j02)

Others described a more reciprocal relationship that was more or less on their terms: "It's important to guard the hard walls between the newsroom and marketing department, but that is an old-fashioned point of view. [...] All types of doors are being opened." (j06). Some mentioned that if advertisers pay enough money, they can take up a dominant space on the website, but control is always kept by the newsroom. For example, in the case of a scheduled news event that will be reported on extensively by the newsroom (e.g., football championships, the Olympic Games, etc.), these plans will be shared with the commercial departments to offer advertisers connected to that news event to buy advertising space. The other way around (having an advertiser suggest a topic to report on) was highly unlikely to non-existent, because this would threaten their independent coverage, and as j02 said: "Would be the beginning of the end". In line with this, those who mentioned fashion magazines as an addition to the news content, considered these magazines fair game for advertisers.

"It could be that the fashion section is being sold for a month, that an advertiser will be added and that we're asked to reach a certain number of visitors. [ . . ] those are thing that I follow up on and translate to my journalists." (j01)

"Readers know that: 'oh, this is about fashion, of course it has a lot of ads about fashion'. They aren't going to say: 'this is all bought or I won't see the difference between an ad and a news story' But if in that magazine a piece gets published on how well a brand does, then they might start asking questions." (j05)

Especially, journalists at digital-only news media seemed to approach the relationship with advertisers in a more pragmatic way: "It's a paid article, but I made sure it's a real 
article. I don't know if you can call it native advertising. It was more a paid collaboration. [ ... ] We made sure it corresponded with our values." (j13). On the one hand, j13 tried to find a new balance between the advertiser and the news medium by looking for shared values. On the other hand, the relationship between the newsroom and the advertiser becomes quite close this way.

\section{Discussion and Conclusions}

\subsection{Certain Degree of Systems Thinking, but Limited View on Value Exchange}

By using a stakeholder marketing lens, this study uncovered how journalists perceive the duality between democratic and financial goals at news media in regards to their important stakeholders. In general, the journalists we spoke to seem to recognise stakeholders within the ecosystem and its current tensions (high systems thinking), but they have a limited view of the value exchange that happens between their newsrooms and the primary stakeholders. This limited view of the stakeholder system leads to only recognising dyadic relationships with one stakeholder at a time, in which tensions are being avoided by disconnecting from stakeholders (advertisers) or by maintaining traditional walls and separation (readers). Paradoxical thinking has been defined as the "capability to accept and learn from the tension between stakeholder interests, rather than to ignore or suppress the tension" (Hillebrand et al. 2015, p. 418). Thus, the interviewed journalists seem to be lacking the skill of paradoxical thinking. Journalists also believe that they have to withstand all influence from other stakeholders like advertisers and readers. They are not inclined to redraw the power dynamics between different stakeholders in the journalistic product development to resolve existing tensions or to expand the value exchange (democratic thinking).

Journalists seem to hold on to traditional role perceptions and see themselves as in the service of the reader. They have a complex view of the value they offer to readers, but believe only the monetary value of readers is essential for the news medium. This seems to have led to a more favourable attitude towards subscribers and the devaluation of nonpaying readers, which do seem to have less value to offer them. Other types of values that subscribers, but also non-paying readers, might offer, like feedback, engagement, content, etc., are considered nonessential and peripheral. This means that the interviewees did not pursue this value in their job and were seemingly not planning to do so in the future. Their newsrooms did not support interaction between journalists and readers systematically, but instead looked at implementing it only in one-off prestige projects and installed another person, the moderator, to deal with comments. This shows that newsrooms are giving more importance to their community of readers, but by assigning a specific person with the task to engage with this community instead of incorporating it in all journalists' job descriptions, one could argue this actually increases the distance between the audience and individual journalists. As concluded by Wolfgang et al. (2020) these moderators are barely accepted by the journalism professionals and they carry little legitimacy to influence the journalistic professional norms. So, our study further confirms that implementing moderators to deal with comments does not seem to fulfil its role of bridging the gap between the audience and the newsroom. Instead, interviewed journalists actually pass the responsibility of interacting with the audience on to these moderators or community editors. Thus, instead of decreasing the distance between the audience and newsroom with moderators, it actually seems to maintain the wall and preserves the traditional professional autonomy from audience involvement.

\subsection{Lack of Paradoxical Thinking: Avoiding Rather Than Navigating Tensions}

In regard to advertisers, any commercial influence needed to be rejected, whereas subscribers, a commercial concept, were held in high regard and determined to some level the editorial decision making of the interviewees. Rather than seeing the tensions with advertisers as a challenge to be resolved, they do not try to rebalance the relationship between news media, advertisers, and readers. Instead, they reject advertisers even more and focus on one group with monetary value that they believe creates the least tensions 
and supports them most: subscribers. This seems to be supported by the belief that the decline in ad revenue has unshackled their newsroom to pursue revenue that is not tainted by commerciality: subscriptions. They also seem to believe that the dual model does not work anymore and that by focusing on subscriptions their news medium will survive. This is in contrast with the current struggles of media to generate enough reader revenue and the uncertainty as to whether this revenue source can actually support journalism on its own (Chyi and Ng 2020). For smaller, less-established news media (often digital-only) it seems harder to discard advertising revenue and withstand commercial pressure. In this study, this was mainly due to the fact that they were still developing a sustainable business to support their journalism.

News media's growing dependence on reader revenue has created a contradiction between journalists' anti-commercial stances and an increased focus on obtaining reader revenue. The study by Duffy and Cheng (2020) revealed that reframing the editorialcommercial relationship to validate it according to existing ideas, is one of the strategies among editors to deal with the cognitive dissonance regarding the commercial-editorial relationship. In line with this, journalists seem to redefine "subscribers" as a purely commercial concept to one that fits these traditional role perceptions better. Subscribers are supporters of the newsroom, even though the main value interviewees sought in readers is monetary in nature. The existence of subscribers confirms journalists' perceptions of the values they bring to readers and the idea that quality always finds its (paying) audience, even though subscribers are only a fraction of their audience (Chyi and Ng 2020). This shows how journalists seem to have developed some paradoxical thinking skills in regard to subscribers to resolve tensions there, but more out of necessity and as an option with less resistance. In contrast, tensions with advertisers were considered to be proof of a bad relationship that should be untangled or broken up completely.

\subsection{Lack of Democratic Thinking: Reluctance to Share Control with Readers}

Despite this strong focus on reader revenue, there seems to exist a reluctance to involve readers in their product development and to fulfil subscribers' needs too much, consistent with previous research by Duffy et al. (2018). Audience metrics are a broadly used and accepted way to understand readers' needs, but it makes feedback dependent on the type of metrics chosen by the news medium and newsroom (Lamot and Paulussen 2020). Moreover, as interviewees deemed the insights from metrics as useless to guide their editorial decisions, there are not any feedback loops in place to evaluate their work from the point of view of readers, except for the yearly renewal of a subscription. Without applying democratic thinking via, e.g., feedback loops or intricate insights into the needs of their audience, product development at newsrooms becomes difficult, but interviewees did not seem motivated to increase their understanding of the audience to improve their news services in the future. It shows how even to their most valuable stakeholder, who they consider crucial for the financial sustainability of their newsroom, journalists are not allowing a stronger voice in journalistic product development and the newsroom's daily activities.

These results imply that the sustainable development and implementation of other value creations in relation to multiple stakeholders, like native advertising, reader panels, comment sections, and user-generated content within news media, become more challenging as journalists seem to refrain from paradoxical and democratic thinking. Moreover, this might complicate the development of entrepreneurial journalists within news media, a group considered by some scholars as crucial for innovation within news media (Boyles 2016), because entrepreneurial journalists can be supposed to implement stakeholder thinking to develop new services and products, with a balance between the editorial and financial goals of the news media.

The growing dependency on subscriptions as a main revenue source also seems to lead to a more vigorous battle with other news media to lead the news cycle in order to maintain their audience's perception of being on top of things and not trailing behind. If 
the percentage of people who are willing to pay for news does not increase and news media continue to go all-in on subscriber revenue, the battle to attract and maintain those few people who are willing to pay for news will rage, possibly leading to increasing power for paying readers.

\subsection{Limitations and Future Research}

News media have both a commercial and editorial side, the publisher and newsroom, respectively. In this study we only shed light on the editorial side. Looking into the publisher's perception of the ecosystem (stakeholders, value exchange, and tensions) might give a different and more comprehensive view. If news media have to deal with the opposing views of the ecosystem of internal stakeholders, this might negatively impact the implementation of innovation. Within journalism studies, this side has largely been underexposed and perhaps its influence also underestimated.

In this study, we also focused on journalists, because they are central to the journalistic process and an important starting point to explore the multi-stakeholder system. However, these results indicate that further studies should explore how readers, subscribers, and advertisers perceive the stakeholder ecosystem and value exchange. This might reveal discrepancies between implicit and explicit assumptions about the needs of other stakeholders and their actual reported needs. Studies by Costera Costera Meijer (2021) on valuable journalism from the audience's point of view revealed that audience's perceptions of valuable journalism do not always coincide with what journalists regard as good journalism.

The qualitative insights from this study could also be further enhanced with quantitative and qualitative studies on the practical implications of a stronger focus on subscribers within the newsroom. If newsrooms continue to focus more on the needs of paying readers and discard non-paying readers' needs, this could mean that over time access to journalism and more importantly agenda-setting (the impact on what topics are covered) becomes the privilege of a small highly educated and financially strong group.

Adopting a commercial entity (subscribers) within their journalistic role perception could lead to the development of subscription-focused analytics-like conversion as a way to measure the value of journalistic output. As journalists seem to understand pursuing subscribers as a compromise between financial and democratic goals, they might accept this and absorb it into their journalist practice. Journalism scholars need to continue studying these changes in audience analytics, especially with keeping the development of algorithms in mind, where the reasoning behind an evaluation is not always transparent, in order to make sure the democratic role of journalists is not diluted by commercial goals.

As a final note, we want to emphasize that this study's exploratory nature makes it difficult to offer generalizable insights that transcend its locality. The way a society is structured changes the level of influence of certain stakeholders. Societies with endangered press freedom, a different market system, or a strong (or weak) public broadcaster can have a completely different stakeholder ecosystem of news media. Nevertheless, applying a stakeholder marketing framework to qualitative methods can help to expose these intricate relationships and how they influence strategies and newsroom decision making.

Author Contributions: Conceptualization, D.L. and S.P.; methodology, D.L. and S.P.; formal analysis, D.L.; writing —original draft preparation, D.L.; writing—review and editing, S.P.; supervision, S.P. All authors have read and agreed to the published version of the manuscript.

Funding: This research was funded by Research Foundation—Flanders (FWO), grant number 1S46720N.

Institutional Review Board Statement: The study was conducted according to the guidelines of the Declaration of Helsinki, and approved by the Institutional Review Board (or Ethics Committee) of The Faculty of Social Sciences at the University of Antwerp (SHW_20_102, 16 November 2021).

Informed Consent Statement: Informed consent was obtained from all subjects involved in the study.

Conflicts of Interest: The authors declare no conflict of interest. 


\section{Appendix A. Interview Protocol}

Good morning, thank you for participating. As agreed previously via email, this conversation will be recorded but the data will be anonymized, so it will not be possible to connect it back to you. The interview will be about $1.5 \mathrm{~h}$. During that time, we will talk about stakeholders. These are the groups that have a stake in the wellbeing of news media. If necessary, give the example of the car industry: tire supplier, employees, police, cities, GPS companies, etc.

Phase 0: intro

Could you please describe your job?

Phase I: identifying stakeholders

1. If you could think about news media and how they function: which group is according to you the most important stakeholder? Are there others?

To be asked for each important stakeholder:

2. How important is that stakeholder? And why?

3. How would you describe the relationship?

4. Do you see them as a friend or enemy? Why?

5. Do you feel like the relationship has changed the past years? Improved or deteriorated?

6. Do you have contact with that stakeholder? Why (not)?

7. How would that interaction go?

8. Whose role is it to deal with this stakeholder? Why?

9. What goes well in this relationship? What works less? Are there major hurdles?

10. If you are working, do you think about this stakeholder?

11. How can the relationship between this stakeholder and your newsroom be improved?

12. What does the stakeholder want according to you?

13. How do you know this?

14. Is it important for a journalist to know what this stakeholder wants?

15. How important is that knowledge to do your job well?

16. In which situations is it useful to work with this stakeholder?

17. What lines are drawn in such a collaboration.

18. Have there been collaborations?

19. How did these go?

20. Does this happen regularly?

21. Who takes charge of such a collaboration?

Phase II: creating the stakeholder map with the power/interest grid by Mitchell et al. (1997)

22. Where would you place this stakeholder? Why there?

23. After placing all mentioned stakeholders;

24. Where would you place journalists?

25. Has it always been like this? What has changed? Is it still changing?

Phase III: evaluating the stakeholder network

26. Is this the most ideal situation? Should something change according to you?

27. What might happen if the needs of <stakeholder 1 with high power and high interest $>$ and <stakeholder 2 with high power and high interest $>$ would be in conflict?

28. Have there been situations like that?

29. How were they resolved?

Phase IV: outro

30. Do you think it is useful to think about stakeholders?

31. What questions were difficult to answer?

32. Have things caught your eye during the conversation?

33. Do you have anything else to add? 


\section{References}

Amazeen, Michelle A., and Bartosz W. Wojdynski. 2019. Reducing Native Advertising Deception: Revisiting the Antecedents and Consequences of Persuasion Knowledge in Digital News Contexts. Mass Communication and Society 22: 222-47. [CrossRef]

An, Soontae, and Lori Bergen. 2007. Advertiser Pressure on Daily Newspapers: A Survey of Advertising Sales Executives. Journal of Advertising 36: 111-21. [CrossRef]

Aribarg, Anocha, and Eric M. Schwartz. 2019. Native Advertising in Online News: Trade-Offs Among Clicks, Brand Recognition, and Website Trustworthiness. Journal of Marketing Research 57: 20-34. [CrossRef]

Artemas, Katie, Tim P. Vos, and Margaret Duffy. 2018. Journalism Hits a Wall: Rhetorical construction of newspapers' editorial and advertising relationship. Journalism Studies 19: 1004-20. [CrossRef]

Bærug, Jan Richard, and Halliki Harro-Loit. 2012. Journalism Embracing Advertising as Traditional Journalism Discourse Becomes Marginal: A comparative study of European MICE (Meetings, Incentives, Conferences and Events) magazines. Journalism Practice 6: 172-86. [CrossRef]

Benson, Rodney. 2018. Paywalls and public knowledge: How can journalism provide quality news for everyone? Journalism 20: 146-49. [CrossRef]

Boyles, Jan Lauren. 2016. The Isolation of Innovation: Restructuring the digital newsroom through intrapreneurship. Digital Journalism 4: 229-46. [CrossRef]

Carlson, Matt. 2015. When news sites go native: Redefining the advertising-editorial divide in response to native advertising Journalism: Theory, Practice E Criticism 16: 849-65. [CrossRef]

Carroll, Joshua. 2019. Reuters article highlights ethical issues with native advertising. CJR. Available online: https://www.cjr.org/ watchdog/reuters-article-thai-fishing-sponsored-content (accessed on 29 September 2021).

Chyi, Hsiang Iris. 2005. Willingness to Pay for Online News: An Empirical Study on the Viability of the Subscription Model. Journal of Media Economics 18: 131-42. [CrossRef]

Chyi, Hsiang Iris. 2012. Paying for What? How Much? And Why (Not)? Predictors of Paying Intent for Multiplatform Newspapers. International Journal on Media Management 14: 227-50. [CrossRef]

Chyi, Hsiang Iris, and Ori Tenenboim. 2017. Reality Check: Multiplatform newspaper readership in the United States, $2007-2015$. Journalism Practice 11: 798-819. [CrossRef]

Chyi, Hsiang Iris, and Yee Man Margaret Ng. 2020. Still Unwilling to Pay: An Empirical Analysis of 50 U.S. Newspapers' Digital Subscription Results. Digital Journalism 8: 526-47. [CrossRef]

Clarkson, Max B. E. 1995. A Stakeholder Framework for Analyzing and Evaluating Corporate Social Performance. The Academy of Management Review 20: 92. [CrossRef]

Coddington, Mark. 2015. The Wall Becomes a Curtain: Revisiting journalism's news-business boundary. In Boundaries of Journalism: Professionalism, Practices and Participation. In Shaping Inquiry in Culture, Communication and Media Studies. Edited by Matt Carlson and Seth C. Lewis Lewis. New York: Routledge, p. 232.

Coddington, Mark. 2018. Seeing Through the User's Eyes: The Role of Journalists' Audience Perceptions in Their Use of Technology. Electronic News 12: 235-50. [CrossRef]

Coddington, Mark, Seth C. Lewis, and Avery E. Holton. 2018. Measuring and Evaluating Reciprocal Journalism as a Concept. Journalism Practice 12: 1039-50. [CrossRef]

Corbin, Juliet M., and Anselm Strauss. 1990. Grounded theory research: Procedures, canons, and evaluative criteria. Qualitative Sociology 13: 3-21. [CrossRef]

Cornia, Alessio, Annika Sehl, and Rasmus Kleis Nielsen. 2018. 'We no longer live in a time of separation': A comparative analysis of how editorial and commercial integration became a norm. Journalism 21: 172-90. [CrossRef]

Costera Meijer, Irene. 2020. Understanding the Audience Turn in Journalism: From Quality Discourse to Innovation Discourse as Anchoring Practices 1995-2020. Journalism Studies 21: 2326-42. [CrossRef]

Costera Meijer, Irene. 2021. What is Valuable Journalism? Three Key Experiences and Their Challenges for Journalism Scholars and Practitioners. Digital Journalism, 1-23. [CrossRef]

Cottle, Simon, and Mark Ashton. 1999. From BBC Newsroom to BBC Newscentre: On Changing Technology and Journalist Practices. Convergence 5: 22-43. [CrossRef]

Cziehso, Gerrit P. 2017. Making Money with Paid Content: Empirical Investigations on Consumers' Reactions to Free-to-Fee Switches and Preview Characteristics. Ph.D. dissertation, Technische Universität Dortmund, Dortmund, Germany. Available online: https:/ / eldorado.tu-dortmund.de/bitstream/2003/36217/1/Dissertation_Cziehso.pdf (accessed on 22 September 2021).

De Smet, Dries, and Stijn Vanormelingen. 2011. Advertiser Pressure on Newspaper Journalists: A Survey. Available online: https:/ / www.researchgate.net/publication/254420741_Advertiser_Pressure_on_Newspaper_Journalists_A_Survey (accessed on 12 September 2021).

Deuze, Mark. 2005. What is journalism? Professional identity and ideology of journalists reconsidered. Journalism 6: 442-64. [CrossRef]

Driessen, Paul H., and Bas Hillebrand. 2013. Integrating Multiple Stakeholder Issues in New Product Development: An Exploration: Multiple Stakeholder Issues in NPD. Journal of Product Innovation Management 30: 364-79. [CrossRef]

Duffy, Andrew, and Lydia Cheng. 2020. It's Complicated: Cognitive Dissonance and the Evolving Relationship Between Editorial and Advertising in US Newsrooms. Journalism Practice, 1-16. [CrossRef] 
Duffy, Andrew, Rich Ling, and Edson C. Tandoc. 2018. The People Have Spoken (The Bastards?). Journalism Practice 12: 1130-47. [CrossRef]

Ferrer-Conill, Raul, and Edson C. Tandoc. 2018. The Audience-Oriented Editor: Making sense of the audience in the newsroom. Digital Journalism 6: 436-53. [CrossRef]

Fletcher, Richard, and Rasmus Kleis Nielsen. 2017. Paying for Online News: A comparative analysis of six countries. Digital Journalism 5: 1173-91. [CrossRef]

Flick, Uwe. 2018. An Introduction to Qualitative Research. London: Sage Publications.

Frow, Pennie, Janet R. McColl-Kennedy, Toni Hilton, Anthony Davidson, Adrian Payne, and Danilo Brozovic. 2014. Value propositions: A service ecosystems perspective. Marketing Theory 14: 327-51. [CrossRef]

Goldfarb, Avi, and Catherine Tucker. 2012. Shifts in Privacy Concerns. American Economic Review 102: 349-53. [CrossRef]

Goldstein, Daniel G., Siddharth Suri, R. Preston McAfee, Matthew Ekstrand-Abueg, and Fernando Diaz. 2014. The Economic and Cognitive Costs of Annoying Display Advertisements. Journal of Marketing Research 51: 742-52. [CrossRef]

Grubenmann, Stephanie, and Miriam Meckel. 2017. Journalists' professional identity. Journalism Studies 18: 732-48. [CrossRef]

Gustafsson, Karl Erik. 2006. Advertising and the Development of Media: The Forgotten Connection. Journal of Media Business Studies 3: 19-31. [CrossRef]

Han, Jiyoon, Minette Drumwright, and Wongun Goo. 2018. Native Advertising: Is Deception an Asset or a Liability? Journal of Media Ethics 33: 102-19. [CrossRef]

Hanitzsch, Thomas. 2011. Populist disseminators, detached watchdogs, critical change agents and opportunist facilitators: Professional milieus, the journalistic field and autonomy in 18 countries. International Communication Gazette 73: 477-94. [CrossRef]

Hanusch, Folker, Sandra Banjac, and Phoebe Maares. 2020. The Power of Commercial Influences: How Lifestyle Journalists Experience Pressure from Advertising and Public Relations. Journalism Practice 14: 1029-46. [CrossRef]

Hermida, Alfred, David Domingo, Ari Heinonen, Steve Paulussen, Thorsten Quandt, Zvi Reich, Jane B. Singer, and Marina Vujnovic. 2011. The Active Recipient: Participatory Journalism through the Lens of the Dewey-Lippmann Debate. Paper presented at International Symposium on Online Journalism, Austin, TX, USA, April 1-5.

Hillebrand, Bas, Paul H. Driessen, and Oliver Koll. 2015. Stakeholder marketing: Theoretical foundations and required capabilities. Journal of the Academy of Marketing Science 43: 411-28. [CrossRef]

Holton, Avery E. 2016. Intrapreneurial Informants: An emergent role of freelance journalists. Journalism Practice 10: 917-27. [CrossRef]

Huempfner, Lisa, and Dennis A. Kopf. 2017. Using stakeholder marketing and social responsibility for new product development in higher education: A business Spanish model. Journal of Marketing for Higher Education 27: 251-73. [CrossRef]

Hult, G. Tomas M., Jeannette A. Mena, O. C. Ferrell, and Linda Ferrell. 2011. Stakeholder marketing: A definition and conceptual framework. AMS Review 1: 44-65. [CrossRef]

Jackson, Daniel, and Kevin Moloney. 2016. Inside Churnalism: PR, journalism and power relationships in flux. Journalism Studies 17: 763-80. [CrossRef]

Jeon, Doh-Shin, and Nikrooz Nasr. 2016. News Aggregators and Competition among Newspapers on the Internet. American Economic Journal: Microeconomics 8: 91-114. [CrossRef]

Johnson, Brett G., and Caroline Dade. 2019. Local broadcast journalism, user-generated content and boundary work. Media Practice and Education 20: 260-76. [CrossRef]

Ksiazek, Thomas B., Limor Peer, and Andrew Zivic. 2015. Discussing the News: Civility and hostility in user comments. Digital Journalism 3: 850-70. [CrossRef]

Küng, Lucy. 2016. Why is media management research so difficult-And what can scholars do to overcome the field's intrinsic challenges? Journal of Media Business Studies 13: 276-82. [CrossRef]

Laczniak, Gene R., and Patrick E. Murphy. 2012. Stakeholder Theory and Marketing: Moving from a Firm-Centric to a Societal Perspective. Journal of Public Policy \& Marketing 31: 284-92. [CrossRef]

Lamot, Kenza, and Steve Paulussen. 2020. Six Uses of Analytics: Digital Editors' Perceptions of Audience Analytics in the Newsroom. Journalism Practice 14: 358-73. [CrossRef]

Lauerer, Corinna. 2019. Advertising and Journalism. In Oxford Encyclopedia of Journalism Studies. Oxford: Oxford University Press.

Laursen, Jesper. 2018. Native Advertising Trends 2018. Copenhagen: Native Advertising Institute. Available online: https://offers. nativeadvertisinginstitute.com/trends--2018--news--media--industry (accessed on 21 September 2021).

Lewis, Justin, Andrew Williams, and Bob Franklin. 2008. A COMPROMISED FOURTH ESTATE?: UK news journalism, public relations and news sources. Journalism Studies 9: 1-20. [CrossRef]

Lewis, Seth C., Rodrigo Zamith, and Mark Coddington. 2020. Online Harassment and Its Implications for the Journalist-Audience Relationship. Digital Journalism 8: 1047-67. [CrossRef]

Loosen, Wiebke, and Jan-Hinrik Schmidt. 2012. (RE-)discovering the audience: The relationship between journalism and audience in networked digital media. Information, Communication E Society 15: 867-87. [CrossRef]

McNair, Corey. 2018. Global Ad Spending Update. New York: eMarketer. Available online: https://www.emarketer.com/content/globalad-spending-update (accessed on 21 September 2021).

Meyen, Michael, and Claudia Riesmeyer. 2012. Service Providers, Sentinels, and Traders. Journalism Studies 13: 386-401. [CrossRef]

Mitchell, Ronald K., Bradley R. Agle, and Donna J. Wood. 1997. Toward a Theory of Stakeholder Identification and Salience: Defining the Principle of who and What Really Counts. Academy of Management Review 22: 853-86. [CrossRef] 
Newman, Nic. 2019. Journalism, Media, and Technology Trends and Predictions 2019. Oxford: Reuters Institute for the Study of Journalism Oxford, University of Oxford. Available online: https://reutersinstitute.politics.ox.ac.uk/sites/default/files/2019-01/Newman_ Predictions_2019_FINAL_0.pdf (accessed on 21 September 2021).

Nielsen, Rasmus Kleis. 2016. The Business of News. In the SAGE Handbook of Digital Journalism. London: SAGE Publications Ltd, pp. 51-67.

O'Sullivan, John, and Ari Heinonen. 2008. Old Values, New Media. Journalism Practice 2: 357-71. [CrossRef]

Picard, Robert G. 2014. Twilight or New Dawn of Journalism?: Evidence from the changing news ecosystem. Digital Journalism 2: 273-83. [CrossRef]

Picard, Robert G. 2015. Journalists' Perceptions of the Future of Journalistic Work. Oxford: Reuters Institute for the Study of Journalism (University of Oxford). Available online: https://reutersinstitute.politics.ox.ac.uk/our-research/journalists-perceptions-futurejournalistic-work (accessed on 21 September 2021).

Picard, Robert G., and Gregory Ferrell Lowe. 2016. Questioning media management scholarship: Four parables about how to better develop the field. Journal of Media Business Studies 13: 61-72. [CrossRef]

Pujol, Enric, Oliver Hohlfeld, and Anja Feldmann. 2015. Annoyed Users: Ads and Ad-Block Usage in the Wild. Paper presented at the 2015 Internet Measurement Conference, Tokyo, Japan, October 28-30.

Rafter, Kevin. 2016. Introduction: Understanding where entrepreneurial journalism fits in. Journalism Practice 10: 140-42. [CrossRef]

Rosen, Jay. 2006. The People Formerly Known as the Audience. Huffington Post (blog). Available online: https://www.huffpost.com/ entry/the-people-formerly-known_1_b_24113 (accessed on 17 November 2021).

Schmidt, Thomas R., Jacob L. Nelson, and Regina G. Lawrence. 2020. Conceptualizing the Active Audience: Rhetoric and Practice in "Engaged Journalism". Journalism 23: 3-21. [CrossRef]

Singer, Jane B., and Marcel Broersma. 2020. Innovation and Entrepreneurship: Journalism Students' Interpretive Repertoires for a Changing Occupation. Journalism Practice 14: 319-38. [CrossRef]

Skibinski, Matt, and Price Rande. 2019. Building Subscriptions and Memberships for Quality Journalism. Philadelphia: The Lenfest Institute, Available online: https://www.lenfestinstitute.org/lenfest-institute-digital-content-next-building-subscriptions-membershipquality-journalism/ (accessed on 17 November 2021).

Stern, Reuben J. 2008. Stakeholder Theory and Media Management: Ethical Framework for News Company Executives. Journal of Mass Media Ethics 23: 51-65. [CrossRef]

Strömbäck, Jesper, and Michael Karlsson. 2011. Who's Got the Power? Journalism Practice 5: 643-56. [CrossRef]

Swart, Joëlle, Chris Peters, and Marcel Broersma. 2018. New Rituals for Public Connection: Audiences' Everyday Experiences of Digital Journalism, Civic Engagement, and Social Life. In Managing Democracy in the Digital Age. Edited by Julia Schwanholz, Todd Graham and Peter-Tobias Stoll. Cham: Springer International Publishing, pp. 181-99.

Taylor, Charles R. 2017. Native Advertising: The Black Sheep of the Marketing Family. International Journal of Advertising 36: 207-9. [CrossRef]

Trappel, Josef, and Tales Tomaz. 2021. Solid performance, but democratic deficits remain: Conclusions. In The Media for Democracy Monitor 2021: How Leading News Media Survive Digital Transformation. Edited by Josef Trappel and Tales Tomaz. Gothenburg: Nordicom, vol. 2, pp. 425-92.

van der Wurff, Richard, and Klaus Schoenbach. 2014. Civic and Citizen Demands of News Media and Journalists: What Does the Audience Expect from Good Journalism? Journalism E Mass Communication Quarterly 91: 433-51. [CrossRef]

Vos, Tim P., and Jane B. Singer. 2016. Media Discourse About Entrepreneurial Journalism: Implications for journalistic capital. Journalism Practice 10: 143-59. [CrossRef]

Walker, Mason, Laura Silver, Elisa Shearer, and Katerina Eva Matsa. 2018. Western Europeans Under 30 View News Media Less Positively, Rely More on Digital Platforms Than Older Adults. Washington, DC: Pew Research Center. Available online: https:/ / www.pewresearch.org/journalism/2018/10/30/western-europeans-under-30-view-news-media-less-positively-relymore-on-digital-platforms-than-older-adults / (accessed on 15 October 2021).

Wenzel, Andrea, and Jacob L. Nelson. 2020. Introduction "Engaged" Journalism: Studying the News Industry's Changing Relationship with the Public. Journalism Practice 14: 515-17. [CrossRef]

Westlund, Oscar, Arne H. Krumsvik, and Seth C. Lewis. 2021. Competition, Change, and Coordination and Collaboration: Tracing News Executives' Perceptions About Participation in Media Innovation. Journalism Studies 22: 1-21. [CrossRef]

Wielki, Janusz, and Janusz Grabara. 2018. The Impact of Ad-Blocking on the Sustainable Development of the Digital Advertising Ecosystem. Sustainability 10: 4039. [CrossRef]

Witschge, Tamara, and Gunnar Nygren. 2009. Journalistic Work: A Profession Under Pressure? Journal of Media Business Studies 6: 37-59. [CrossRef]

Wojdynski, Bartosz W. 2016. Native advertising: Engagement, deception, and implications for theory. In The New Advertising: Branding, Content and Consumer Relationships in a Data-Driven Social Media Era. Edited by Ruth E. Brown, Valerie K. Jones and Ming Wang. Santa Barbara, CA: Praeger/ABC Clio, pp. 203-36.

Wolfgang, J. David, Stephen McConnell, and Hayley Blackburn. 2020. Commenters as a Threat to Journalism? How Comment Moderators Perceive the Role of the Audience. Digital Journalism 8: 925-44. [CrossRef] 